\title{
O Estágio na Licenciatura em Computação como Espaço para Formação do Professor Pesquisador de sua Prática: Um Relato de Experiência
}

\author{
Veruska Ribeiro Machado ${ }^{1}$, Fabiano Cavalcanti Fernandes ${ }^{1}$ \\ ${ }^{1}$ Instituto Federal de Brasília, Campus Taguatinga \\ QNM 40, AE 01 - CEP 72146-000 - Taguatinga - DF - Brasil \\ \{veruska.machado, fabiano.fernandes\} difb.edu.br
}

\begin{abstract}
This article describes an experience of internship in computer science teaching in compliance with curricular guidelines, investigative, critical and reflective attitude, seeking to research its own practice. Several challenges were encountered in the internship's execution spaces, bringing new opportunities for the intern's action, from partnership with Escola Parque Anisio Teixeira, a model school of the Department of Education of the Federal District up to the creation of an extension course of computational thinking for children of the community, through the code.org platform and unplugged computing, aiming to create a pilot environment conducive to computing education, seeking a contextualized opportunity for learning.
\end{abstract}

Resumo. Este artigo descreve uma experiência de realização de estágio em Licenciatura em Computação ancorado no cumprimento das diretrizes curriculares, com postura investigativa, crítica e reflexiva, buscando pesquisar sua própria prática. Diversos desafios foram encontrados nos espaços de execução do estágio, trazendo novas oportunidades de ação do estagiário, desde a parceria com a Escola Parque Anísio Teixeira, uma escola modelo da Secretaria de Educação do Distrito Federal até a criação de um curso de extensão de pensamento computacional para crianças da comunidade, através da plataforma code.org e da computação desplugada, com objetivo de criar um ambiente piloto favorável ao ensino da computação, buscando uma oportunidade contextualizada para a aprendizagem.

\section{Introdução}

O Art. $4^{\circ}$ da Resolução CNE/CES n ${ }^{\circ}$ 5/2016 [Brasil 2016], que institui as Diretrizes Curriculares Nacionais para os cursos de graduação na área da Computação, em seu parágrafo $5^{\circ}$, indica o perfil do licenciado em Computação, que envolve, dentre outras habilidades, a capacidade de atuar como docentes, em uma atitude investigativa, com visão crítica e reflexiva. Já no Art. $5^{\circ}$ da referida Resolução, que aponta competências e habilidades profissionais que devem ser desenvolvidas no licenciando em Computação,

\footnotetext{
1 Veruska Ribeiro Machado (autor principal/correspondente) - Possui graduação em Letras pela Universidade de Brasília (1997). É especialista em língua portuguesa (2002) pelo Uniceub. É também especialista em Educação para a Diversidade e a Cidadania (2014) e em Gestão de Políticas Públicas de Raça e Gênero (2016). Mestre (2005) e Doutora em Educação pela Universidade de Brasília (2010). Fabiano Cavalcanti Fernandes - Possui graduação em Ciência da Computação pela Universidade Federal da Paraíba (1998), Especialização em Banco de Dados pela Universidade Católica de Brasília (2005), Mestrado em Gestão do Conhecimento e da Tecnologia da Informação pela Universidade Católica de Brasília (2007) e Doutorado em Biotecnologia (Bioinformática) pela Universidade Católica de Brasília (2012).
} 
VI Congresso Brasileiro de Informática na Educação (CBIE 2017)

Anais dos Workshops do VI Congresso Brasileiro de Informática na Educação (WCBIE 2017)

tem-se o reforço da postura investigativa que esses profissionais devem assumir, especialmente nos incisos VIII e IX do parágrafo $5^{\circ}$ :

VIII- atuar como docente com a visão de avaliação crítica e reflexiva;

IX - propor, coordenar e avaliar, projetos de ensinoaprendizagem assistidos por computador que propiciem a pesquisa.

Observa-se, pois, que a Resolução que define as Diretrizes Curriculares para a Formação dos Licenciados em Computação leva em consideração o Professor Reflexivo. De acordo com Schön [Schön 1992], a prática profissional deve ser valorizada por ser uma oportunidade de construir conhecimento partindo-se da reflexão, análise e problematização da prática. A defesa de Schön por uma epistemologia da prática valoriza a pesquisa na ação dos profissionais, lançando as bases para a reflexão acerca do professor pesquisador de sua prática [Pimenta e Lima, 2012]. Dessa forma, constata-se, a partir do discurso das Diretrizes, a valorização da prática na formação dos professores de computação. Essa prática ganha relevância a partir do momento em que os leva a uma reflexão para responder às situações que se colocam no cotidiano.

A valorização da prática refletida encontra-se também na Resolução CNE/CP n ${ }^{\circ}$ 02/2015 [Brasil 2015], que define as Diretrizes Curriculares Nacionais para a Formação de Professores. As bases para a formação de um professor pesquisador de sua prática estão presentes em vários trechos dessa Resolução. Logo no Art. $3^{\circ}$, destaca-se a articulação entre a teoria e a prática no processo de formação docente, fundada no domínio dos conhecimentos científicos e didáticos, contemplando a indissociabilidade entre ensino, pesquisa e extensão $\left(\S 5^{\circ}\right.$, Inciso V). Essa indissociabilidade entre ensino, pesquisa e extensão pode ser alcançada por meio de uma formação que valorize o professor pesquisador de sua prática.

Segundo o Art. $5^{\circ}$ da Resolução, o egresso da formação inicial de professores deve ter uma formação que o conduza à construção do conhecimento, valorizando a pesquisa e a extensão como princípios pedagógicos essenciais ao exercício e aprimoramento do profissional do magistério e ao aperfeiçoamento da prática educativa (Inciso II); e ao acesso às fontes nacionais e internacionais de pesquisa, ao material de apoio pedagógico de qualidade, ao tempo de estudo e produção acadêmica-profissional, viabilizando os programas de fomento à pesquisa sobre a educação básica (Inciso III).

Outros dois artigos da Resolução reforçam o professor como produtor do saber. O Art. $7^{\circ}$ determina que o repertório de informações e habilidades da formação deve permitir aos docentes a pesquisa, a análise e a aplicação dos resultados de investigações de interesse da área educacional e específica (Inciso II). Já o Art. $8^{\circ}$ parte do princípio de que a formação do professor deve deixá-lo apto a:

realizar pesquisas que proporcionem conhecimento sobre os estudantes e sua realidade sociocultural, sobre processos de ensinar e de aprender, em diferentes meios ambientalecológicos, sobre propostas curriculares e sobre organização do trabalho educativo e práticas pedagógicas (Inciso IX). 
Constata-se, pela leitura das resoluções retromencionadas, que teoria e prática são indissociáveis, uma vez que os saberes teóricos se articulam aos saberes da ação docente. Dessa forma, ao mesmo tempo em que os saberes teóricos ressignificam os saberes da ação dos professores, estes ressignificam aqueles. A pesquisa torna-se essencial nesse processo [Sacristán 1999] [Pimenta e Lima, 2012].

Indo ao encontro do que está disposto nas Diretrizes de Formação de Professores e dos licenciados em computação no que se refere à formação de um professor crítico e reflexivo, pesquisador de sua própria prática, o curso de licenciatura em Computação, ofertado pelo Instituto Federal de Brasília (IFB)/Campus Taguatinga, objeto deste relato, compreende: um conjunto de conhecimentos científicos e práticas escolares necessários para que o/a futuro/a educador/a possa assumir a docência, respaldado/a em uma prática reflexiva e crítica, fruto da vivência de trabalho em equipe, projetos, pesquisa, situações de aprendizagem, autonomia, profissionalização e, acima de tudo, compreensão da educação como uma prática social e política [Instituto Federal de Brasília 2013].

Nessa perspectiva, pois, os professores em formação foram encaminhados ao estágio nas escolas da Secretaria de Educação do Distrito Federal. Inicialmente, os licenciandos fizeram pesquisa de campo, de natureza investigativa, para reconhecer o contexto de atuação do professor de informática em algumas escolas de educação básica localizadas nas Regiões Administrativas de Taguatinga Norte e Ceilândia, região em que se encontra o Campus Taguatinga. Os resultados dessa pesquisa foram utilizados para redefinir a proposta de estágio do curso, que será a seguir relatada.

\section{Desafios do Licenciando em Computação em Ambientes de Estágio}

Sabe-se dos desafios enfrentados nos estágios de licenciatura de forma geral. Silva [Silva 2015], ao refletir sobre essa questão, destaca dois extremos que, na concepção do autor, estão presentes nesses estágios: i) o estagiário assume a posição passiva de observador, o que, para Silva, é mais frequente; ii) o estagiário assume a regência da turma em virtude da ausência do professor da sala.

Em relação ao licenciando do curso de Computação, somam-se outros desafios aos enfrentados pelos professores das disciplinas curriculares em formação inicial. Temse, por exemplo, a questão dos laboratórios de informática das escolas (públicas e particulares) de nosso país, que, em algumas, não existem e, em outras, encontram-se fechados ou com equipamentos obsoletos, que impedem seu uso integrado e efetivo.

Ademais, há um questionamento que os licenciandos em Computação enfrentam, em especial, quando adentram as escolas, de viés marcadamente mercadológico: por que formar um licenciado em Computação se não há disciplina obrigatória de Computação no ensino formal? [Castro e Vilarim 2013].

Essa questão, segundo Castro e Vilarim [Castro e Vilarim 2013], adequadamente debatida por Matos e Silva [Matos e Silva 2012], vai além da mera inclusão de outra "matéria" na escola. Matos e Silva destacam que os conhecimentos da computação são fundamentais para a vida social contemporânea e deverão estar presentes, seja como disciplina ou integrados às demais disciplinas, o que requer profissionais de Computação-Educação. 
O fato é que as escolas procuram trazer a informática para o seu cotidiano, mas enfrentam desafios, sendo que um dos principais é a ausência do licenciado em Computação. Relevante também é reconhecer que o lócus de atuação desse profissional não se restringe ao interior da sala de aula, podendo também abranger a construção de softwares educativos e objetos de aprendizagem, a atuação em equipes multidisciplinares, em ambientes de educação formal e não-formal [Castro e Vilarim, 2013].

Dessa forma, um dos desafios enfrentados, que é a ausência de espaço de atuação do professor de informática, pode contribuir para a construção de novos espaços e ampliar essa atuação, oportunidade ideal para o fomento de Aprendizagem das Coisas.

A pesquisa realizada pelos estudantes da Licenciatura em Computação do IFB corrobora outros estudos que apontam os desafios desse profissional, anteriormente apresentados. Os principais achados da investigação são os seguintes: i) falta de conteúdo específico para o ensino de informática; ii) ausência de recursos tecnológicos; iii) falta de planejamento das escolas que envolva a informática em seu Projeto Político Pedagógico; iv) ensino da informática somente como ferramenta ou meio acessório a outras disciplinas; v) ausência de aulas de programação e de pensamento computacional; vi) e a formação docente insuficiente. ${ }^{2}$

Esses resultados foram utilizados no planejamento das atividades de estágio. $\mathrm{Na}$ próxima seção, serão mostradas as estratégias desenvolvidas para dar conta dos desafios apontados pela pesquisa de campo.

\section{Estratégias Desenvolvidas}

Nesta seção, serão apresentadas as estratégias adotadas para o desenvolvimento das atividades de estágio, considerando-se os desafios apontados na pesquisa de campo desenvolvida pelos estudantes da licenciatura em Computação.

\subsection{Estabelecendo Diálogo com a Secretaria de Educação do Distrito Federal}

$\mathrm{Na}$ pesquisa de campo, foram identificados três pontos que estão desenvolvidos nesta subseção: ii) ausência de recursos tecnológicos; iii) falta de planejamento das escolas que envolva a informática em seu Projeto Político Pedagógico; vi) formação docente insuficiente.

Diante dessas questões, fez-se um levantamento das escolas das regiões administrativas pesquisadas que contavam com laboratório de informática. Mesmo tendo esse espaço, o que se percebeu foi a ausência de professores de informática com formação na área que pudessem ser supervisores dos estagiários. Identificou-se também haver lacunas quanto ao planejamento no que se refere à informática nas escolas.

Ante tal situação, o IFB estabeleceu parceria com a Escola Parque Anísio Teixeira (EPAT), localizada em Ceilândia/DF, a única Escola Parque existente fora do Plano Piloto de Brasília, para encaminhamento dos estagiários. A escola conta com laboratório de informática, professor formado na área de Computação e clara definição da relevância da informática na formação básica das crianças e dos jovens.

\footnotetext{
2 Esta pesquisa foi apresentada na $69^{\text {a }}$ Reunião Anual da SBPC (2017). Desenvolveram-na os estudantes Ana Luíza M. Nunes; Christiane N. Pereira; Luiz Ximenes Neto, sob orientação das professoras Fernanda Bezerra M. Martins e Veruska R. Machado
} 
VI Congresso Brasileiro de Informática na Educação (CBIE 2017)

Anais dos Workshops do VI Congresso Brasileiro de Informática na Educação (WCBIE 2017)

O objetivo geral da EPAT é oferecer espaço, tempo e oportunidades formativas aos estudantes nas áreas de Arte, Cultura, Música e Educação Física com vistas ao desenvolvimento integral dos estudantes/comunidade da cidade de Ceilândia [Distrito Federal 2016].

A EPAT desenvolve atividades voltadas a Artes Visuais/ Plásticas, Cênicas, Música, Literatura, Dança, Educação Física e Tecnologia. Seu público consiste em estudantes dos Anos Finais do Ensino Fundamental das Regionais de Taguatinga e Ceilândia. A EPAT oferece atividades de Caráter Complementar, semestral, com atendimento no turno livre do estudante em conformidade com sua opção. A metodologia adotada pela escola são as oficinas de ensino, que são desenvolvidas em uma perspectiva interdisciplinar.

Os estudantes da licenciatura em computação, atualmente, fazem um dos estágios nas oficinas de tecnologia ofertadas pela EPAT. Essas oficinas são ofertadas no matutino e no vespertino, com duração de $1 \mathrm{~h} 15 \mathrm{~min}$. São três turmas em cada turno de segunda-feira a quinta-feira e duas turmas com horário estendido em cada turno na sexta-feira. O objetivo geral das oficinas de Tecnologia é:

Promover o uso pedagógico da informática na Educação Básica, integrando informática educativa com a proposta de ensino pedagógica da escola, a fim de desenvolver diversas habilidades com o uso adequado do computador e de contribuir com a educação do aluno, estimulando o aprendizado ao contemplar as diversas áreas do conhecimento de forma interdisciplinar [Distrito Federal 2016].

Os professores em formação em estágio na EPAT têm a oportunidade de conhecer a escola, os estudantes; de acompanhar o desenvolvimento das atividades didáticas; e de atuar juntamente com o supervisor. Acredita-se que, nesse processo, o aprofundamento teórico-conceitual dos fundamentos da educação deve subsidiar a reflexão acerca das práticas de ensino. Nesse percurso, os professores em formação elaboram um projeto de intervenção em sua prática pedagógica.

O desenvolvimento do projeto de intervenção nessa perspectiva vai ao encontro do que dispõem as Diretrizes citadas na introdução deste trabalho no que se refere à formação do professor pesquisador, uma vez os licenciandos realizam uma pesquisa centrada na realidade da escola, visando a uma transformação. Para desenvolver o referido projeto, os estagiários partem de um determinado problema, buscando contribuir, de alguma forma, para a mudança da realidade.

\subsection{Dialogando Ensino, Pesquisa e Extensão}

Paralelamente ao estágio na Secretaria de Educação do Distrito Federal, desenvolvemse também, no espaço do estágio, atividades de extensão. Essa estratégia foi adotada, principalmente, por causa do que apontou a pesquisa inicial, que reconheceu o contexto de atuação do professor de informática nas escolas próximas à região do Campus: i) falta de conteúdo específico para o ensino de informática; iv) ensino da informática 
VI Congresso Brasileiro de Informática na Educação (CBIE 2017)

Anais dos Workshops do VI Congresso Brasileiro de Informática na Educação (WCBIE 2017)

somente como ferramenta ou meio acessório a outras disciplinas; v) ausência de aulas de programação e de pensamento computacional; e ii) falta de recursos tecnológicos.

Com o objetivo de desenvolver com os estagiários uma proposta que envolvesse conteúdos de informática, planejou-se o curso de extensão denominado Fundamentos de Pensamento Computacional, ofertado a 20 crianças de 8 a 12 anos, moradores da comunidade circunvizinha ao IFB Campus Taguatinga. O objetivo geral do curso foi estimular o desenvolvimento de fundamentos do pensamento computacional. Os objetivos específicos foram: Desenvolver a abstração; Desenvolver a criatividade para a resolução de problemas; Estimular a interação e o trabalho colaborativo; e estimular a autonomia em relação ao uso do computador como forma de empoderamento. Para isso, foram desenvolvidos os seguintes conteúdos: Compreensão de algoritmos; Lógica de programação e detecção e correção de erros.

O curso tomou como base o desenvolvimento de atividades sugeridas no livro Computer Science Unplugged [Bell 2011], que consiste em uma coleção de atividades desenvolvidas com o objetivo de ensinar os fundamentos da Ciência da Computação sem a necessidade de computadores. Além do referido material, o curso também se apoiou nas atividades presentes no web site http://www.code.org, organização sem fins lucrativos dedicada a expandir o ensino de ciência da computação.

$\mathrm{Na}$ próxima seção, encontram-se os resultados oriundos das estratégias desenvolvidas pelos professores da licenciatura em computação para a realização do estágio.

\section{Resultados}

Nesta seção, encontram-se os resultados das atividades desenvolvidas na Escola Parque Anísio Teixeira e nos projetos de extensão.

\subsection{Escola Parque Anísio Teixeira (EPAT)}

Foram desenvolvidos quatro projetos de intervenção na EPAT no primeiro semestre de 2017, conforme constam nas Tabelas 1, 2, 3 e 4. Vale destacar que os projetos foram desenvolvidos em oficinas de $6 \mathrm{~h}$ de duração e que, além da interdisciplinaridade, precisaram abordar o Tema Norteador adotado pela EPAT no $1^{\circ}$ semestre de 2017: Honestidade e Corrupção.

\section{Tabela 1. Atividade desenvolvida de história em quadrinhos como recurso computacional}

\begin{tabular}{|c|c|}
\hline Objetivo Geral & Objetivos Específicos \\
\hline $\begin{array}{l}\text { Promover a reflexão a } \\
\text { respeito da corrupção e } \\
\text { honestidade no âmbito } \\
\text { social com o uso de } \\
\text { ferramentas } \\
\text { tecnológicas e recursos } \\
\text { computacionais }\end{array}$ & $\begin{array}{l}\text { - Utilizar ferramentas computacionais como o software e a } \\
\text { Internet; } \\
\text { - Estimular a criatividade; } \\
\text { - Usar o computador como forma de construção para o } \\
\text { pensamento critico; } \\
\text { - Utilizar o computador como um instrumento de } \\
\text { desenvolvimento tecnológico; }\end{array}$ \\
\hline
\end{tabular}


VI Congresso Brasileiro de Informática na Educação (CBIE 2017)

Anais dos Workshops do VI Congresso Brasileiro de Informática na Educação (WCBIE 2017)

- Trabalhar em equipe;

- Criar histórias em quadrinho utilizando o Pixton (http://www.pixton.com/);

- Estimular o respeito no âmbito social

Tabela 2. Atividade desenvolvida de segurança digital e ética no meio virtual

Projeto de intervenção $n^{\circ} 2$ : segurança digital e ética no meio virtual

\section{Objetivo Geral}

Transformar usuários da rede em cidadãos mais conscientes

na

utilização da tecnologia e na promoção e acesso às informações contidas no mundo virtual, desenvolvendo tópicos atuais relacionados ao cotidiano do usuário de internet.

\section{Objetivos Específicos}

- Ensinar a origem histórica da criptografia computacional e suas aplicabilidades computacionais (História Geral e Computação);

- Ensinar como criar um alfabeto criptografado e solicitar que os alunos digitem frases sobre corrupção e honestidade criptografadas;

- Ensinar os principais tipos de ataques e fraudes na Internet;

- Ensinar padrões éticos na utilização de dados e informações encontradas na rede;

- Estimular o bom uso da Internet (Ética e Computação)

Tabela 3. Atividade desenvolvida de Honestidade e Corrupção: o que é ser honesto?

Projeto de intervenção $n^{\circ}$ 3: Honestidade e Corrupção: o que é ser honesto?

Objetivo Geral

Esclarecer aos alunos a

diferença

honestidade

corrupção

ferramentas

tecnológicas e estimular

atitudes éticas que

favoreçam

honestidade.

\section{Objetivos Específicos}

- Favorecer a compreensão dos conceitos de honestidade e corrupção

- Estimular o desenvolvimento de atitudes de solidariedade, de cooperação e repúdio às injustiças

- Desenvolver o senso crítico

- Estimular o uso de ferramentas de pesquisa

- Favorecer a compreensão do que é a cidadania como participação social e política

Tabela 4. Atividade desenvolvida de criação de animações interativas com software de desenho: usando o tema Honestidade e Corrupção

Projeto de intervenção $n^{\circ} 4$ : criação de animações interativas com software de desenho: usando o tema Honestidade e Corrupção

\begin{tabular}{|l|c|}
\hline Objetivo Geral & Objetivos Específicos \\
\hline $\begin{array}{l}\text { Desenvolver animações } \\
\text { usando como suporte }\end{array}$ & $\begin{array}{l}\text { Participar na produção de uma animação e ter contato com } \\
\text { os conteúdos de artes visuais, que se baseia na reflexão, na }\end{array}$ \\
\hline
\end{tabular}


VI Congresso Brasileiro de Informática na Educação (CBIE 2017)

Anais dos Workshops do VI Congresso Brasileiro de Informática na Educação (WCBIE 2017)

\begin{tabular}{|l|lr|}
\hline $\begin{array}{l}\text { de ensino } \\
\text { aprendizagem o tema } \\
\text { sugerido } \\
\text { coordenação da EPAT a } \\
\text { respeito de práticas de } \\
\text { honestidade } \\
\text { corrupção }\end{array}$ & e & - $\begin{array}{l}\text { Trabalhar com a oficina de Tecnologia } \\
\text { Desenvolver habilidades de animação em software } \\
\text { específico }\end{array}$ \\
& $\begin{array}{l}\text { Propiciar um ambiente em que os alunos possam dar } \\
\text { opiniões sobre ser verdadeiro: não mentir, não fraudar, não } \\
\text { enganar. }\end{array}$ \\
& $\begin{array}{l}\text { Estimular a criação, imaginação, capacidade de reflexão, } \\
\text { capacidade apreciação, capacidade de produção, } \\
\text { desenvoltura e ética } \\
\text { Utilizar imagens, áudio e vídeo como ferramentas de } \\
\text { disseminação do conhecimento }\end{array}$ \\
\hline
\end{tabular}

\subsection{Curso Fundamentos de Pensamento Computacional}

O curso teve a sua primeira edição no primeiro semestre de 2017. Participaram dele 20 crianças entre 8 e 12 anos. A experiência com a primeira edição do curso foi registrada em diário de bordo para posterior análise das potencialidades e fragilidades da experiência.

Como potencialidades, observou-se que as estratégias adotadas auxiliaram os alunos a desenvolver maior nível de abstração ${ }^{3}$ e de resolução dos exercícios, valorizando o erro como relevante para a produção de novos saberes. Já em relação às fragilidades, apontam-se: i) conhecimentos prévios como, por exemplo, a lateralidade; e a falta de habilidades como localização espacial, atenção e abstração.

\subsection{Outras Atividades de Pesquisa e Extensão Relacionadas ao Estágio}

O desenvolvimento, nos professores em formação, da relevância de ser pesquisador de sua própria prática incentivou-os a propor projetos de pesquisa e extensão que tivessem como lócus de investigação a sala de aula, atividades estas desenvolvidas também como atividades de estágio. No final do primeiro semestre de 2016, 4 projetos de iniciação científica foram aprovados com esse viés, conforme Tabela 5. Deve ser destacado que os projetos citados envolveram a realização de oficinas, desenvolvidas pelos próprios estagiários.

\section{Tabela 5. Projetos de Iniciação Científica que foram desdobramentos das atividades de estágio desenvolvidas pelos alunos da Licenciatura em Computação do IFB Campus Taguatinga}

\begin{tabular}{|c|l|}
\hline 1 & $\begin{array}{l}\text { Lógica de programação no ensino fundamental e seus efeitos sobre o ensino de } \\
\text { matemática }\end{array}$ \\
\hline 2 & $\begin{array}{l}\text { Prototipagem 3D como ferramenta de empoderamento educacional de estudantes do } \\
\text { Curso Técnico Integrado em Eletromecânica e do Programa Nacional de Integração da } \\
\text { Educação Profissional com a Educação Básica na Modalidade de Educação de Jovens e } \\
\text { Adultos (Proeja em Artesanato)do IFB Campus Taguatinga }\end{array}$ \\
\hline 3 & Robótica Educacional como Estratégia Pedagógica \\
\hline
\end{tabular}

\footnotetext{
3 Análise feita pelos licenciandos em Computação Guilherme Carvalho Rodrigues e Laureane Pereira de Sousa
} 
VI Congresso Brasileiro de Informática na Educação (CBIE 2017)

Anais dos Workshops do VI Congresso Brasileiro de Informática na Educação (WCBIE 2017)

4 A tecnologia auxiliando no desenvolvimento escolar de alunos com transtorno de déficit de atenção/hiperatividade

\section{Considerações Finais}

Os conceitos de professor crítico e reflexivo e de professor pesquisador, subjacentes nas Diretrizes Curriculares citadas na introdução deste texto e no Projeto Pedagógico do Curso objeto deste relato indicam sua importância para que os estágios sejam realizados como pesquisa e para que as pesquisas neles realizadas também sejam utilizadas. Nesse sentido, os currículos de formação docente devem valorizar a pesquisa oriunda da prática docente no desenvolvimento das atividades de estágio.

Observa-se que não há, de forma generalizada, um ambiente favorável à aprendizagem da computação nos espaços pesquisados nas cidades satélites de Taguatinga e Ceilândia. O IFB Campus Taguatinga, com seus eixos tecnológicos de Automação Industrial, Eletromecânica e Computação, através de projetos de pesquisa e extensão na área de Educação e Internet das Coisas, pode se apresentar como um catalisador do ensino da computação na região em que atua, contribuindo para um aprendizado contextualizado e para a criação de novos modelos educacionais.

Uma postura investigativa do Licenciado em Computação traz benefícios à formação dos estudantes do ensino fundamental e médio, através de novos modelos educacionais e novas tecnologias aplicadas. Para isso ocorrer, durante a sua formação, o estágio deve ser um espaço favorável ao ensino da computação, oferecendo um momento de aprendizagem contextualizada.

Como trabalhos futuros, propõe-se a investigação das impressões dos licenciandos em relação à proposta apresentada, inclusive como forma de avaliação das atividades desenvolvidas no estágio. Também propõe-se uma investigação junto aos alunos de educação básica que participaram dos projetos e das oficinas.

\section{Referências}

Bell, T. (2011). "Ensinando Ciência da Computação sem o uso do computador", http://csunplugged.org/wp-content/uploads/2014/12/CSUnpluggedTeachersportuguese-brazil-feb-2011.pdf.

Brasil. Ministério da Educação (2016). "Diretrizes Curriculares Nacionais para os cursos de graduação na área da Computação", Resolução CNE/CES 5/2016. Diário Oficial da União, Brasília, 17 de novembro de 2016, Seção 1, págs. 22-24.

Ministério da Educação (2015). "Diretrizes Curriculares Nacionais para a formação inicial em nível superior (cursos de licenciatura, cursos de formação pedagógica para graduados e cursos de segunda licenciatura) e para a formação continuada". Resolução CNE/CP 2/2015. Diário Oficial da União, Brasília, 2 de julho de 2015 - Seção 1 - pp. 8-12. Retificação publicada no DOU de 3/7/2015, Seção 1, p. 28. Alterada pela Resolução CNE/CP n 1 , de 9 de agosto de 2017.

Castro, C. S.; Vilarim, G. O. (2013) Licenciatura em Computação no cenário nacional: embates, institucionalização e o nascimento de um novo curso. Revista Espaço Acadêmico, no 148, p. 18-25, Setembro/2013. 
VI Congresso Brasileiro de Informática na Educação (CBIE 2017)

Anais dos Workshops do VI Congresso Brasileiro de Informática na Educação (WCBIE 2017)

Distrito Federal. Secretaria de Estado de Educação (2016). Projeto Político Pedagógico Escola Parque de Ceilândia Anísio Teixeira.

Gimeno Sacristán, J. (1999). "Poderes instáveis em educação”. Porto Alegre: Artmed Sul.

Instituto Federal de Brasília (2013). "Resolução no 21/2013/CS-IFB. Autoriza a oferta do Curso Superior em Computação - ABI (Licenciatura em Computação) e aprova seu respectivo projeto pedaógico de curso".

Matos, E. S.; Silva, G. F. B. da. (2012). "Currículo de licenciatura em computação: uma reflexão sobre perfil de formação à luz dos referenciais curriculares da SBC". In: XX Workshop sobre Educação em Computação, 2012, Curitiba. Anais do XXXII CSBC.

Pimenta, S.G.; Lima, M.S.L. (2012). "Estágio e docência". São Paulo, Cortez Editora.

Schön, Donald A. (1992). "Formar professores como profissionais reflexivos". In: Nóvoa, António (Coord.). Os professores e sua formação. Lisboa: Dom Quixote.

Silva, V. P. (2015). "Estágio supervisionado no contexto profissional contemporâneo: tempo de formação e de produção de riqueza". In: Silva Júnior, C. A.; Gatti, B. A.; Mizukami, M. G. N.; Pagotto, M. D. S. \& Spazziani, M.L. (Orgs.) Por uma revolução no campo da formação de professores. SP: Editora Unesp. 